\title{
Valuing and adapting appreciative inquiry to enhance well-being using a neuropsychotherapeutic framework
}

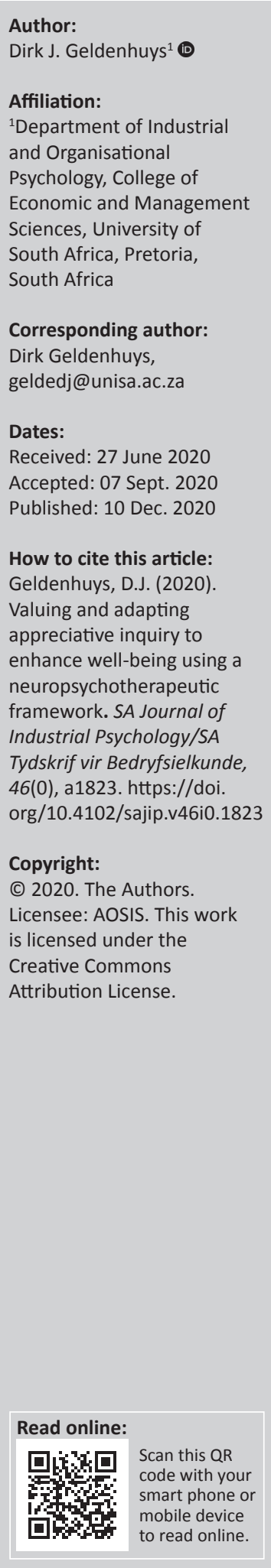

Orientation: Considering the impact of the unprecedented worldwide changes on employee well-being; well-being will increasingly become a competitive edge for organisations. The focus of this study was on appreciative inquiry (AI) as intervention for well-being; to hypothesise why and under what circumstances AI could be effective, and what can be performed to enhance its effectiveness, especially in respect of improving the well-being of employees.

Research purpose: The purpose of this study was to valuate and refine AI as an intervention aimed at facilitating well-being in the workplace, using a neuropsychotherapeutic approach as framework.

Motivation for the study: Appreciative inquiry is well known in the management and organisational sciences as an approach and a method to facilitate change. Despite the importance of well-being for organisations, in the academic literature, reporting on the use of $\mathrm{AI}$ as an intervention to facilitate well-being remains largely limited. Furthermore, no evidence of a similar study using a neuropsychoterapeutic framework could be found in the English literature.

Research approach/design and method: This was a conceptual analysis with theory adaption as an approach. Appreciative inquiry was chosen as a domain theory and neuropsychotherapy as a method theory. Firstly, AI was discussed, after which the focus fell on neuropsychotherapy with the focus on well-being. Neuropsychotherapy was then used to evaluate and refine AI as an intervention directed at well-being.

Main findings: It was found that neuropsychotherapy served as a valuable method theory to refine AI for enhancing well-being.

Practical/managerial implications: Appreciative inquiry in its more traditional form can be used to facilitate employee well-being in general but will probably be less effective in changing hard-wired neural circuits for the better. For employees who experience high levels of stress, a refinement of $\mathrm{AI}$ is needed, in line with neuropsychotherapy.

Contribution/value add: This study contributed to the literature on well-being interventions.

Keywords: appreciative inquiry; memory systems; neural networks; neuropsychotherapy; well-being; interventions; organisations.

\section{Introduction}

Considering the impact of the unprecedented worldwide changes on employee well-being; wellbeing will increasingly become a competitive edge for organisations. With the influence of appreciative inquiry (AI) on the development of positive organisational behaviour (POB) concept and on the strengths-based movement (Bushe, 2011), the argument put forward in the literature is that AI can be used to promote well-being (Lewis, 2016; Lewis, Passmore, \& Cantore, 2011; Moore \& Charvat, 2007; Nel \& Govender, 2019; Trajkovski, Schmied, Vickers, \& Jackson, 2013). According to Lewis (2014, p. 232), AI 'can be seen as an approach that offers a pragmatic methodology for putting some of the findings from positive psychology to practical effect in an organization'. This article is about valuing and refining $\mathrm{AI}$ as a strengths-based intervention, aimed at enhancing well-being in organisations, using a neuropsychotherapeutic framework.

Bushe (2011) echoes Head (2005) by stating that further research on AI is required to explain the contingencies and moderators that influence the effectiveness of related interventions. Notably, 
pertinent research is mostly based on measuring the effects or outcomes of interventions at the expense of investigating the interventions themselves (Biron, Karanika-Murray, \& Cooper, 2012). In this conceptual analysis, the focus is on the development of the intervention per se to hypothesise why and under what circumstances it could be effective, and what can be performed to enhance its effectiveness, especially in respect of improving the well-being of employees.

Here, an argument is made for the relevance of using a neuropsychotherapeutic framework. Grawe (2007) pioneered neuropsychotherapy in answer to questions about the type of therapy that would emerge if problems related to the practice of therapy were approached from a neuroscientific perspective. Neuropsychotherapy, therefore, differs from all other forms of therapy as it focuses on the neural processes underlying human responses such as sensations, memory, emotions, thoughts, behaviours and relationships, and hence, the onset of pathology and wellness (Rossouw, 2014). From this perspective, the aim of neuropsychotherapy is to constrain the activation of those previously acquired neural circuits that are responsible for pathology and replace them with new neural circuits that will allow individuals to function and engage in relationships more effectively. The activation of new neural pathways should, however, be experienced not only in a therapeutic situation but also in real-life circumstances (Grawe, 2007). To this end, neuropsychotherapeutic methods and principles to enhance wellness should also be applied in the workplace (Habermacher, Ghadiri, \& Peters, 2014; Henson \& Rossouw, 2013; Pillay, 2011).

It is argued that applied neuroscience as an interdisciplinary field of study offers a scientific theoretical framework that serves as a benchmark for assessing, expanding on, or refining existing theories, and even proposing new theories and practices aimed at facilitating well-being in the workplace. More precisely, for the purpose of this article, neuropsychotherapy offers a method for valuating and refining AI as a strengths-based intervention. The premises of this argument is that neuropsychotherapy is regarded not only as a stand-alone theoretical method through which to comprehend and facilitate wellness, but also as a meta-theory that suggests baseline principles for other methods of wellbeing (Rossouw, 2014). Neuropsychotherapy differs from other methods in the sense that it does not promote a specific school in psychology or psychotherapy, but focuses on the neural principles underlying the essence of all human functioning (and hence well-being), while offering neuroscientific guidelines to facilitate optimal functioning (Cozolino, 2017; Grawe, 2007; Rossouw, 2014). Furthermore, it does not compartmentalise biology and psychology either but advocates an integrative, systemic approach (Arden, 2019). Importantly, more recent approaches to both neuropsychotherapy and AI have incorporated the principles of self-organising systems in their respective theorising (see Arden, 2019; Bushe, 2011).

The purpose of this article is thus to apply neuroscientific principles - as embedded in neuropsychotherapy - to the domain of $\mathrm{AI}$ as a strengths-based intervention. It, therefore, constitutes an attempt to contribute to the refinement of an intervention and thereby to bridge any disparities that may occur between theory and practice (Nielsen, Taris, \& Cox, 2010), with a view to laying a foundation for future empirical studies.

\section{Research design \\ Research approach}

This was a conceptual analysis with theory adaption as an approach (Jaakkola, 2020). Appreciative inquiry was chosen as a domain theory and neuropsychotherapy as a method theory (Lukka \& Vinnari, 2014). Theory adaptation contributes by offering a new or alternative perspective on an existing conceptualisation (MacInnis, 2011).

\section{Research method}

Firstly, AI is discussed as domain theory, after which the focus falls on neuropsychotherapy as a method theory with the focus on well-being. The method theory is used to evaluate $\mathrm{AI}$ as an intervention directed at well-being, indicating the value as well as the shortcomings thereof. The discussion concludes with recommendations on refining the intervention, with a view to enhancing well-being.

\section{Targeted body of literature}

Scholarly books of seminal authors were primarily consulted. These sources offer integrated, consolidated perspectives on the concepts. To identify current developments, the literature was then augmented with e-journals retrieved from EBSCOHOST, Emerald, Google Scholar, Science Direct and ProQuest. Access was obtained through http://www.unisa. ac.za/library web portal.

\section{Data gathering method}

Inclusion and exclusion criteria were applied to the e-journals. Only peer-reviewed articles, published in English, were included. Articles regarded as irrelevant were excluded. Keywords used in the search included AI and well-being (19 articles) and AI and neuroscience ( 2 articles). No articles on a concept analysis of AI using neuropsychotherapy as method theory could be found.

\section{Data analysis and presentation}

Links were made between the domain theory and the method theory, and theoretical explanations for the links were offered to serve as a ground for the claims being made on the value and refinement of $\mathrm{AI}$ as intervention to well-being in the workplace (Hirschheim, 2008; Jaakkola, 2020).

\section{Appreciative inquiry}

Appreciative inquiry emerged as a research method that is primarily based on social constructionism (Watkins, Mohr, \& Kelly, 2011), and eventually became an alternative to the 
traditional problem-solving approach and method of organisational change (Bushe, 2011). Firstly, the word 'appreciate' refers to the act of valuing the best in people (their strengths and potential) and 'perceiv[ing] those things that give life (health, vitality, excellence) to living systems' and secondly, to an increase in value (Cooperrider \& Whitney, 2005, p. 7). 'Inquiry' refers to the act of identifying and exploring potentials and opportunities: 'AI involves the art and practice of asking unconditionally positive questions that strengthen a system's capacity to apprehend, anticipate, and heighten positive potential' (Cooperrider \& Whitney, 2005, p. 8).

With no universally accepted definition of $\mathrm{AI}$ and even variances between academics and practitioners (Bushe 2001), recent content analysis revealed seven fundamental conceptual categories on which different definitions of AI were built, namely 'best in people', 'asking positive questions', 'positive potential', 'mobilizes inquiry', 'best practices', 'builds momentum' and 'life giving forces' (Charag \& Fazili, 2017). The authors also identified concerns about the 'possibility that a focus on positive stories and experiences will invalidate the negative organizational experiences of participants and repress potentially important and meaningful conversations that need to take place' (Charag \& Fazili, 2017, p. 6). However, they also identified counterarguments positioning AI as more than studying 'the best of' and bringing greater reflexivity to AI practice (Charag \& Fazili, 2017, pp. 6-7). Founded on their analysis, they offer the following comprehensive definition that can be regarded as relevant for both academic and practitioner perspectives: 'Appreciative Inquiry in a central way includes art and practice of asking positive questions to mobilize inquiry about best practices among people so that a positive potential can build momentum to identifying life giving forces to a system and thereby providing a way to embrace organizational change'. This definition seems to be in line with the shifts in thinking to not focus so much on the positive as an end, but more towards the generative capacity of AI (Grieten et al., 2018). This shift is visible, for instance, in the development of reflexive inquiry (RI) as a consultancy framework that draws on practices emanating from social constructionism, including AI (Oliver, 2005).

\section{Underlying principles}

The unique strength of AI can be attributed to the integration of a new paradigmatic perspective grounded in social constructionism and the offering of a practical process in facilitating transformation in complex human systems (Watkins et al., 2011). Although augmented with other principles in recent years and a shift in focus on the relative importance, the following core principles were originally identified as providing a paradigmatic basis for $\mathrm{AI}$, and being crucial to any related intervention (Barrett \& Fry, 2005; Reed, 2007; Stratton-Berkessel, 2010):

- Social constructionism, with its generative view on the role of dialogues, is fundamental to AI. According to the constructionist principle, conversation is at the core of human functioning; it creates knowledge and meaning and is the seed from which action sprouts. Words are not used only to describe objects: reality is created through the words people use when engaging in dialogue.

- The simultaneity principle postulates that change is not linear; the process starts with the very first question we ask. The manner in which questions are crafted is thus crucially important, and hence implies a moment of choice. Asking unconditionally positive questions helps to inspire positive future images and action (StrattonBerkessel, 2010).

- According to the poetic principle, what we focus on, grows. When we study a piece of art or listen to music with endless possibilities of interpretation, we all bring our own interpretations of our experiences to conversations, thereby contributing to different perspectives, learning and inspiration. The metaphors we use shape our beliefs.

- The positive principle resembles the 'broaden-and-build theory' (Fredrickson, 2002, 2009), in accordance with which positive emotions expand our openness to others, along with our attention and thinking, and also deepen our positive emotional reserves. Positive emotions enable us to cope better with the unknown and with change. A deliberate choice of positive words and questions will enhance creativity and the possibility of a thriving future.

- The anticipatory principle states that the images we form about the future direct our behaviour. In line with the placebo effect (Chaplin, 2006), the stories we tell ourselves are fulfilled. Images of health and well-being, for instance, set in motion the necessary bodily mechanisms for healing and recovery. During AI, 'the collective image of the future, as projected in ongoing conversations and categories of discourse, guides what there is to notice in the present, and by doing so, structures action' (Barret \& Fry, 2005, p. 47).

With the evolvement of AI, more principles were added: the wholeness principle that refers to the interconnectedness of systems, people and even dichotomous ideas (Watkins et al., 2011); the enactment principle whereby images and visions of a desired future are enacted in the present moment; the principle of free choice according to which people will be more enthusiastic and committed if they are free to choose their terms of contribution (Whitney \& Trosten-Bloom, 2003); and the narrative principle with the focus on the act of sharing stories as a catalyst for change (Barret \& Fry, 2005).

\section{Appreciative inquiry process}

The above-mentioned principles of $\mathrm{AI}$ are integrated in practice. The typical AI process known as the 4-D cycle, consists of four different phases. An alternative 5-D cycle differs from the 4-D cycle by including a 'define phase' (see below), as an equivalent to the affirmative topic choice (Barret \& Fry, 2005; Cooperrider \& Whitney, 2005; Watkins \& Mohr, 2001). 


\section{Define or affirmative topic choice}

As human beings are inclined to focus on problems, an AI intervention often commences with the process of reframing the problem in such a manner that it 'most captures what people are really curious about, what they really want to see as a desired outcome of working together' (Barrett \& Fry, 2005 , p. 75). Topics are identified that serve as the basis for discovery interviews (Cooperrider \& Whitney, 2005).

\section{Discover}

The discovery phase of the AI process begins with appreciative interviews through one-on-one dialogue, to uncover the positive core of the system or the life-giving forces that are evident when the system is functioning at its best. These dialogues are based on the topic of investigation, and the questions posed are formulated in an unconditionally positive manner. Stories that are deeply valued, persistent and durable not only become powerful sources for future reference but sharing them also initiates creative interaction and assists in building powerful relationships (Barret \& Fry, 2005).

\section{Dream}

This phase involves the creation of a results-oriented vision, based on the strengths and potential that were discovered during the interviews. Participants are invited to use their imagination to discuss what life would look like, if their strengths and aspirations were fully aligned. The envisioned dream of what might be is often expressed as a form of art (Cooperrider \& Whitney, 2005).

\section{Design}

The design phase refers to the social architecture of the envisioned system. Possibility propositions of what the ideal should be, and the enabling mechanisms needed to facilitate change, are co-created. These possibility propositions serve as a bridge between the best of what is and the collective aspirations of what might be (Barrett \& Fry, 2005).

\section{Destiny}

During the destiny phase, people self-organise and commit to action that will enable the whole system to move towards to realise its dreams and sustain the change process (Barrett \& Fry, 2005; Cooperrider \& Whitney, 2005).

Although the approach is still applied at large-scale organisational systems, such as the use of AI summits, group and individual levels, often for team building and coaching purposes (Lewis, 2016; Orem, Binkert, \& Clancy, 2007), of late the inclusion of another phase called 'drench', or 'living the dream', after dream and before design is proposed by Sankarasubramayan and Wasundhara (2019). According to the authors (2019, p. 51), 'To Drench is to stay in the energy of the dream, to "just be" and suspend all actions'. This phase allows for a process of letting go of the old letting waiting for the new.

\section{The role of appreciative inquiry interviews}

The discovery phase of AI begins with appreciative interviews, often following a stage-setting introduction (Lewis et al., 2011). With the emphasis on social constructionism as a paradigmatic foundation for $\mathrm{AI}$ (Watkins et al., 2011), the appreciative interview, also referred to as a form of dialoguing or sharing stories (Berrett \& Fry, 2005) by asking questions related to highpoints, valuing and what gives life to organisations at its best, is 'at the heart of $\mathrm{AI}^{\prime}$ (Cooperrider \& Whitney, 2005, p. 14).

The purpose of appreciative interviewing is to not only to provide rationally derived ideas, but also to produce rich embodied descriptions of personal experiences of past events (the discovery phase), future possibilities (dream phase), transition (design phase) and intent (destiny phase) (Lewis et al., 2011). The infinite number of possible stories about the same event provides the resource for organisational change. Sharing these 'personal moments' creates a climate for collective dreaming (Bushe, 1998).

The use of language plays a crucial role during appreciative interviews as the questions asked during the interview already impact the dynamics of the relationship in the current moment. 'The questions we ask determine what we find, and what we find escalates in our language, in our dialogue, in our conceptualizations and very much takes part in the social construction of reality' (Grieten et al., 2017, p. 104).

The experience of positive emotions as supported by Martin Seligman's classification of happiness (Seligman, 2002; Seligman \& Csikszentmihalyi, 2014) and more specifically Barbara Fredrickson's 'broaden-and-build theory' (Fredrickson, 2009) also play a significant role in AI (Lewis et al., 2011; Stratton-Berkessel, 2010; Watkins et al., 2011; Whitney \& Fredrickson, 2015). Fredrickson (2002) distinguishes between physical sensations, moods and emotions by pointing out the cognitive evaluative component of emotion. According to the broadening hypothesis, positive emotions broaden a person's momentary action repertoire, and according to the building hypothesis, experiences of positive emotions build people's enduring personal resources. To the extent that positive emotions broaden and build, over time they improve wellbeing. As positive emotions broaden the scope of cognition and enable flexible and creative thinking, they should enhance the development of resilience (Fredrickson, 2002). Applied in organisational context, Lewis et al. (2011) similarly argue that combining positive emotions such as passion, hope and confidence with a powerful vision will increase our resilience. Positive and negative states take energy 'and positive emotion-based energy is a powerful resource for change' (Lewis et al., 2011).

Also, asking positive questions does not mean 'mindless happy talk' whereby problems are ignored - they are just approached from the other side. Issues presented by clients are therefore paraphrased to demonstrate an understanding of the issue before the conversation is directed towards what 
they want more of (Cooperrider \& Whitney, 2005, p. 5). According to Lewis et al. (2011), the focus on appreciation is to balance our well-developed critical skills.

Furthermore, by acknowledging the critique on AI's focus on the positive (Barge \& Oliver, 2003), Fry and Cooperrider argue that positive emotion is a necessary but insufficient condition and that more inquiry is needed in the experience of the 'power of the whole'. Fry is of opinion that the focus was too much on appreciation at the expense of inquiry and that appreciation should be just one way of inquiry (Grieten et al., 2017). This argument seems to support the seemingly increasingly emphasis on social constructionism as paradigm with its focus on the generative power of engaging in relational processes and practices (Anderson, 2019; Gergen, 1991; Gergen \& Gergen, 2003).

\section{Appreciative inquiry and change}

Despite case studies where AI was not successful (Bushe, 1998; Bushe \& Kassam, 2005), there is enough documented evidence to support claims regarding the success of AI in facilitating transformation in complex human systems on all levels, such as individual, dyad, group, team, family, organisation and community levels; for an array of interventions, such as team building, strategic planning, performance appraisals, global summits, coaching and wellbeing; and in different types of organisations (Moore \& Charvat, 2007; Watkins et al., 2011).

For AI to be transformative, the focus should not be on only sharing those stories that we want to hear. For instance, according to Bushe (1998), AI can change the stories in the 'inner dialogue' that serve as a stabilising force and prevents follow-through on rational decisions. Similarly, Barrett and Fry (2005) argue that AI can create spaces for diverse stories to be heard. Bushe (1998) maintains that appreciating all stories can evoke new stories and images in which even paradoxes can be resolved (Bushe, 1998). Although still a challenge in AI, 'AI scholars have initiated an ongoing search into "how to inquire into the full spectrum of organizational life generatively so that the transformational potential of AI is advanced"' (Grieten et al., 2017, p. 112).

New images direct behaviour as if it is already happening. Social constructionism plus the power of image equals $\mathrm{AI}$ in organisational change (Watkins et al., 2011). Therefore, according to Bushe and Kassam (2005) to be transformative, AI needs to focus on how people think instead of what they do, and on supporting self-organising processes that flow from new ideas. Furthermore, according to Cooperrider (Grieten et al., 2017), images create new learning that can be regarded as 'anticipatory learning' in which new possibilities are envisioned. Appreciative inquiry, as a change theory, will thus be most productive as it is applied to build resilience before trauma is experienced.

\section{Appreciative inquiry and well-being}

Regarding the improvement of health or well-being, Moore and Charvat (2007) showed the uniqueness of AI by comparing models of behaviour change, such as those based on social learning, cognitive-behaviour, trans-theoretical models and those with components related to more affirmative philosophies. Examples of the latter include motivational interviewing, learned resourcefulness, imagery and resiliency. In contrast to AI, motivational interviewing does not entail dialoguing, while learned helpfulness includes a problem-solving component. Resiliency and imagery are comparable to AI, with imagery using similar techniques as AI during the dream and discovery phases (Moore \& Charvat, 2007). The authors define imagery as 'a mind-body intervention that uses an individual's imagination to change physical, emotional, or spiritual characteristics by forming a mental representation of an object, place, or situation' (Moore \& Charvat, 2007, p. 568).

\section{Neuropsychotherapy as a method theory}

Since the ground-breaking research of Eric Kandel (1998), the focus in neuroscience has shifted from an electrochemical or pharmacological approach, to one which views the brain as a comprising complex, self-organising system (Grawe, 2007; Rossouw, 2014; Siegel, 2012) composed of 'multiple, distinct, and interacting networks that support complex cognitive and emotional functioning' (Wilkinson, 2017, p. 88). The self is thus not fixed, but is rather a complex, adaptive system that emerges through 'self-organizing feedback loops between cortical, subcortical, and body states and the meaning making capacity we call the mind' (Arden, 2019, p. 4). Integrating and balancing these subsystems or mental networks are regarded as crucial for the maintenance of a coherent and adaptive mind, and represent an important focus of therapy. When the mind functions optimally, the fulfilment of bodily needs is balanced with adapting to a changing environment.

\section{Neural networks}

Current neuropsychotherapeutic approaches have seen three networks or operating systems emerge as critically important for healthy mental functioning (Arden, 2019; Cozolino, 2017; Lanius, Frewen, Tursich, Jetly, \& McKinnon, 2015; Wilkinson, 2017), and these are listed below.

\section{Executive network}

The executive network (EN), being the last part of the brain to develop, is only fully formed in the individual's midtwenties (Rossouw, 2014). Described as the chief executive officer of the brain (Arden, 2019), it manages the other systems and is also responsible for complex decision-making, working memory and initiating and sustaining goal-directed behaviour (Wilkinson, 2017). Goal-directed behaviour is performed by using working memory to consciously attend 
to and linking together the complexities of the task at hand (Arden, 2019, p. 10). Information is retrieved from the explicit memory and meaning is created by organising an array of different facts and putting them into words.

When the EN has not fully developed yet or does not function optimally, attention disorders, a lack of spontaneity or resilience in respect of decision-making might be experienced (Arden, 2019). For instance, without establishing good connections and integrations with other networks, it would be difficult to make sense of, or to apply, information, which would result in an overwhelming overload of information (Rossouw \& Rossouw, 2017).

The experiential nature of AI allows for stimulating and exercising EN functions throughout the process. Working memory, a core component of the EN is, for example, used when themes are identified during the discovery phase and goal-directed behaviour is of relevance, especially during the design and destiny phases of AI when people self-organise and commit to action.

Furthermore, it seems that during the design and destiny phases, the focus shifts form self-reflection to the outside world. The safe space created during the preceding phases serves to enhance the activation of the EN, resulting in better planning, decision-making and more goal-directed behaviour (Dahlitz, 2015; Dahlitz \& Rossouw, 2014). Only once a sense of safety has been created during the discovery phase, and positive expectations have been imagined during the dream phase of the AI, can the optimal activation of the EN occur. The sequence of the phases could also serve to balance the fulfilment of inner needs with the ability to confront the challenges posed by the environment.

\section{Default-mode network}

The default-mode network (DMN), also referred to as the story brain (Arden, 2019), is to a large extent involved in self-referential thoughts and feelings (Buckner, AndrewsHanna, \& Schacter, 2008). When the DMN is activated, the mind is largely detached from the external environment and falls back into a 'resting state' (Arden, 2019, p. 13), with the EN not attending to experiences in that moment. The DMN plays a significant role in developing a sense of self by establishing a reciprocal connection between others and the self. It allows the individual to self-reflect, focus on relationships, assumes the perspective of others and imagines the future outcomes of interpersonal behaviour (Buckner \& Carroll, 2006; Cozolino, 2017). Detachment from the environment provides an opportunity not only to reflect on past experiences but also to daydream. As the mind needs predictability (Rossouw, 2014), the processing of past experiences and daydreaming about future possibilities help it to function optimally, and provide the basis for creativity (Cozolino, 2017).

The over-activation of the DMN might, however, lead to rumination on negative past experiences, instead of considering positive future possibilities. This, in turn, may adversely impact a person's sense of control, self-efficacy and self-esteem, and hence lead to rigidity and even depression (Arden, 2019).

The DMN derives its information from both the explicit and the implicit, but mainly from the latter memory systems (Arden, 2019), which contain both procedural and emotional sub-systems, leading to the formation of habits. The development of habits initially involves input from the EN, but as neurons that wire together fire together (Hebb, 1949), habits become automatic after repetition (Arden, 2019).

However, implicit memories are profound, difficult to change and provide a template for new learning. Feelings related to past experiences are thus reactivated in the current moment and also used to project future experiences (Arden, 2019; Cozolino, 2017).

By discovering and aligning best practices and using these to create better futures, AI seems to focus on changing these memory systems related to the DMN. Opportunities for reflection on and sharing positive or strength-based stories can thus be regarded as an attempt to develop a more coherent DMN. The mutual sharing and combining of strengths could enhance the development of the DMN even more.

The more recent focus of AI on inquiry instead of the over focus on appreciation (Grieten et al., 2017) that allows for sharing and appreciating 'dark' stories, may create an awareness of these unwanted memories, and sharing different stories can provide different perspectives that is also conducive for learning and change. 'The mutual exploration of values, commitments, and moralities as well as relational communities that give them sustenance - can allow participants to collaborate even when they differ over those values, commitments and moralities' (Hoskin \& McNamee, 2006, p. 25).

\section{Salience network}

The salience network (SN) is also known as the feeling network (Arden, 2019). Emotions emerge as stimuli from the autonomic nervous system and are expressed as positive feelings when retrieved in the present moment (Henson \& Rossouw, 2013; Wilkinson, 2017). Awareness and processing of these emotions lead us to experience ourselves as emotional human beings (Arden, 2019). Importantly, where unconscious emotional states automatically signal danger or benefit, conscious feelings help us to adapt to the world by recruiting our cognitive abilities (Damasio \& Carvalho, 2013; LeDoux \& Damasio, 2013).

The SN assists the EN in choosing and maintaining the focus of attention on internal or external stimuli, to guide our emotional and interpersonal responses (Cozolino, 2017). It therefore mediates between the other two networks (Menon \& Uddin, 2010), 'between outer and inner 
awareness and cognitive and affective experiences' (Wilkinson, 2017, p. 91) and between the 'emotional feelings of being an individual and the feelings of being with other individuals' (Arden, 2019, p. 9). This connection also allows for top-down reappraisal and emotional regulation. In this sense, the $\mathrm{SN}$ can thus be viewed as the meaning-making network of bodily, emotional and cognitive experiences (Wilkinson, 2017).

The SN derives its information from an implicit, unconscious, emotional memory system and is hence especially activated when potential threats to safety are detected or when the fulfilment of basic human needs such as the need for control and orientation, attachment, pleasure maximisation or pain avoidance and self-esteem is impeded (Grawe, 2007; Rossouw, 2014). Over-activation of the SN can lead to an increase in threat-sensitivity, hyperarousal, hypervigilance and anxiety, while under-activation to emotional detachment and a lack of motivation (Lanius et al., 2015; Wilkinson, 2017).

The $\mathrm{SN}$ is largely activated when personal experiences are shared during the AI process. Telling a story is an embodied experience that activates emotions. When a person shares a memory of a personal nature, neural pathways similar to the original experience are activated, and therefore, the original emotions, state of arousal and muscle tone are reactivated and re-experienced in the body (Lewis et al., 2011). The experiential nature of the AI process may thus, for instance, enable participants to set goals that are of personal value and thereby directing behaviour to these and increase commitment to execute them during the design and destiny phases.

\section{Neuroscience of well-being}

To ensure well-being, specialisation of the systems in their unique functioning as discussed above, together with maintaining a balance and co-ordination between these different systems through both positive and negative feedback loops into a functional whole, is crucial (Arden, 2019; Cozolino, 2017; Siegel, 2012). Cozolino (2017) differentiates between top-down integration encompassing bodily, emotional and conscious awareness, and left-right integration of the left and right regions of the brain. The left regions are largely associated with approach motivation and positive emotions, and the right brain with avoidance motivation and negative experiences (Cozolino, 2017).

During optimal functioning, the activation of the DMN assists in providing stability by reflecting on the past and envisioning the future, while the activation of the EN creates the capacity to dynamically engage with the challenges of the environment in the present moment. The SN serves as a 'switch' between these two networks by determining the relevance and urgency of dealing with outside challenges or personal needs. 'A secure adult flexibly shifts from the DMN to the EN to focus attention on cognitively demanding tasks while maintaining activity in the salience network for self-awareness' (Arden, 2019, p. 51). If the demands of the environment are too high, change is experienced as chaotic and leads to anxiety. However, too much stability causes rigidity and leads to depression (Arden, 2019). Developing well-being can thus be regarded as maximising the flexible zone between personal stability and the capacity to adapt to a changing environment, and this is made possible by the lifelong capacity of the brain to modify in respect of its structure and function, known as neuroplasticity (Rossouw, 2014).

At times, changing rigid implicit memories such as those related to routine behaviour or unwanted emotional responses requires unlearning. These memories can in most instances be unlearnt by activating or developing preferred memories through new learning in areas such as the EN. This type of learning and unlearning is especially relevant for skills development and resource utilisation (Ecker, Ticic, \& Hulley, 2012) and is to a large extent implied in cognitive behavioural therapy (Cozolino, 2017; Rossouw, 2014). As emotional learning related to the implicit memory system is stronger than that of explicit learning, the chances of reverting to old responses remains likely. To establish new neural connections, several repetitions of the new learning are required, over time (Ecker et al., 2012).

However, especially during times when the functioning of the EN is compromised by strong past or present emotional memories, a cognitive understanding of the inappropriate feelings alone is not enough for change to happen (Ecker, 2018). Learning then requires an integration within and balancing or co-ordination between the systems, thus between positive and negative emotions, and between emotions and cognition (Cozolino, 2017; Ecker et al., 2012).

It therefore stands to reason that balancing between the networks will best be facilitated in those instances by the simultaneous activation of, and oscillation between, the different networks (Ecker, 2018). This can be affected, for instance, through the use of language, narratives and autobiographical memory (Rossi, 1993; Siegel, 2012). 'Autobiographical memory creates stories of the self [which is] capable of supporting affect regulation in the present and the maintenance of homeostatic functions into the future' (Cozolino, 2017, p. 49). Vacillating between sharing positive and negative experiences, for example, instils a sense of hope as it creates the expectation that the negative will be followed by positive experiences.

Visual images also play an important role in facilitating the integration of and balancing between neural networks (Cozolino, 2017). As the DMN does not differentiate between images of past experiences and future images, images can be used to assist in creating futures as if this has already happened. This can assist not only with creating better futures, but also with priming the brain for possible future challenges (Rossouw, 2014). To add, combining linear stories and visual imagery with emotional awareness and expression 
will even further enhance the integration between the different networks.

Another form of neural plasticity, known as memory reconsolidation (Alberini, 2013; Ecker et al., 2012; Ross et al., 2017), is relevant especially for undoing those implicit emotional memories that inhibit the functioning of the EN to deal appropriately with challenges. This is achieved through a process whereby the unwanted emotional memory is reactivated, and a mismatch is created by identifying or creating another, more positive memory. A seemingly similar process is followed in brain working recursive therapy (BWRT), where outdated memories are interrupted and replaced with new, better memories imagined by the client (Nel \& Govender, 2019). This is performed through a process of oscillating between images of the past unwanted memory, a better memory and an excellent future memory.

\section{Discussion}

The purpose of this article is to evaluate and refine AI as a strengths-based intervention aimed at enhancing wellbeing. The discussion will offer propositions on the strengths of the AI approach for facilitating well-being, after which possible refinements to enhance the process will be proposed.

\section{Valuating appreciative inquiry}

The AI process, to a large extent, relies on the use of conversations or story-telling about positive experiences or current strengths, values about the self and wishes for the future, elicited during the discovery phase of the intervention. With this in mind, it is postulated that AI creates relational spaces of psychological safety 'where curiosity reigns, where new possibilities are considered and embraced' (Barrett \& Fry, 2005, p. 98). The experience of safety serves to help develop a more coherent DMN, by making the SN more biased towards the EN instead of the DMN (Arden, 2019; Rossouw, 2014). A safe context is thus created that could impede the over-activation of the DMN and assist in diminishing defensiveness and thereby preventing people from ruminating on negative past experiences (Cozolino, 2017; Williams, 2014). It thus provides prospects for self-reflection and optimism. As it could be a challenging experience for some people to reflect and share in a different way comparing to what they are used to, reflection may also provide optimal levels of stress that is conducive for change to happen.

More specifically, sharing autobiographical memories in the present moment could aid in enhancing the connections between the EN and the DMN as it permits outside experiences to be connected with self-reflection, thereby opening up new, future possibilities and planting the seeds of creativity (Arden, 2019; Cozolino, 2017). 'The combination of a linear storyline with visual imagery woven together with verbal and non-verbal expressions of emotion activates and utilises dedicated circuitry of both left and right hemispheres, cortical and sub-cortical networks, the various regions of the frontal lobes, and the hippocampus and the amygdala' (Cozolino, 2017, p. 187). Sharing positive stories about the self can impact on altering negative self-beliefs and, linking these stories with envisioning an ideal future, can improve personal stability even more.

Furthermore, focusing on positives and strengths might enhance well-being by enabling the experience of control and the development of self-esteem (Arden, 2019; Henson \& Rossouw, 2013). A coherent DMN is crucially important for raising self-awareness and developing self-esteem, as well as empathy (Cozolino, 2017). 'By reflecting on the past and projecting to positive futures, we use our DMN to maintain continuity over time and use our EN and salience network to think or feel in the present moment' (Arden, 2019, p. 15). Sharing a story about the self becomes a template for action that can develop into a self-fulfilling prophecy (Cozolino \& Sprokay, 2006).

Sharing stories also enables interpersonal integration, as stability and growth development in response to relationships (Arden, 2019; Siegel, 2012). The SN enhances the capacity for self-awareness, but also promotes intuitive feelings about the other person, and hence, the capacity for trust and empathy. Sharing one's own story and listening to another person's story during the discovery phase, activate the DMN of both participants and provide a safe space for co-creating a new narrative. The activation processes involved in satisfying the need for attachment create an optimal environment for neural plasticity (Cozolino, 2017).

The dream phase is used to envision the system when it is functioning at its very best. Using forms of art as an activity to encapsulate that vision builds on the strengths and wishes identified during the discovery phase. It is therefore reasoned that this activity similarly contributes to the development of a more coherent experience, with options for the future leading to a sense of control being experienced (Grawe, 2007; Rossouw, 2014).

The design and destiny phases of AI probably also serve to integrate the SN with its focus on the saliency of emotions and the goal-directed behaviour of the EN, and hence to enhance well-being. As the development of goals during the design phase is based on positive personal experiences and amplified during the dream phase, participants will be committed to enact these goals. Theories of subjective wellbeing suggest that well-being can be enhanced when the goals are self-chosen and of intrinsic value, and that the process of moving towards personal aspirations may be more important to well-being than the end state of goal attainment (Diener, Sue, Lucas \& Smith, 1999).

Although emphasised to a lesser extent in well-being, it can be postulated that AI also facilitates the integration of leftand right-brain regions. As left-brain regions are primarily 
associated with positive emotions and approach motivation and right brain with negative emotions and avoidance motivation (Cozolino, 2017), integration can be facilitated by setting goals in combination with a positive narrative.

Notwithstanding the above, it is argued that if the focus of AI is only on the sharing of positive experiences and strengths, an overly safe environment can be created, without establishing that controlled incongruency (or optimal stress) which serves as a stimulus for change (Cozolino, 2017; Grawe, 2007; Rossouw, 2014). A mild to moderate level of arousal is needed for optimal development and integration (Cozolino, 2017). According to the principles of neuropsychotherapy, the activation of neural networks is needed to make them malleable for change, concurrent with or prior to, new experiences being introduced (Cozolino, 2017). In more recent AI literature, it is acknowledged that, under certain conditions, expressing positive emotions is not generative (Grieten et al., 2018).

Similarly, not allowing for reflection on negative feelings, sensations and thoughts might possibly sustain (or lead to the development of) avoidance behaviour as a mechanism to control negative feelings and thoughts. Even worse - the EN can be used to rationalise and reinforce avoidance behaviour (Cozolino, 2017). Although reframing negative topics as part of the affirmative topic choice might assist in this regard, the contribution of the reframing process to the development of well-being will in all likelihood be limited, because of the cognitive level on which this seems to take place: it excludes related feelings and bodily sensations, and the lack of repetition in the process weakens much-needed connections.

Using AI might also not be conducive in situations where sub-cortical systems are over-activated to such an extent that the capacity of the EN to down-regulate these systems is compromised. If a major imbalance between the EN and the SN exists, and if there is no integration, people might find it difficult to focus on the task at hand, to control their thoughts and feelings or even use their imagination (Cozolino, 2017). Given such a state of mind, the whole AI process might be compromised. In similar instances, merely focusing on the positive will not assist in creating safety, because basic needs will not have been met; thus, the intervention will ultimately not be experienced as meaningful. To balance the activation of the $\mathrm{SN}$ with that of other systems, an intervention needs to be 'emotionally relevant, 'feel' right and [be] meaningful' (Arden, 2019, p. 16). In these situations, it will be conductive to first support the client (Levin, 2008).

In light of the above, it is proposed that AI could enhance well-being, because the process, to a significant extent, serves to integrate (and create a balance between) different neural networks. It will thus assist in developing whole-brain functioning, particularly if the more recent developments in $\mathrm{AI}$ is incorporated.

\section{Refinement of appreciative inquiry for well-being}

To facilitate $\mathrm{AI}$ in organisations for well-being purposes, the process should be refined not to improve the functioning of the different networks only, but also to balance and integrate the different networks.

When facilitating AI in situations where the well-being of participants is already compromised to such an extent that the DMN is biased towards the $\mathrm{SN}$, they might find it difficult to engage the EN. It is recommended that, in these situations, reframing during the define phase be emphasised, to become a core phase of the AI process. The purpose of this phase is not to deal with, or solve, the problems that are presented. Rather, its goal should be to activate the neural networks involved in responding to the impact of the environment and making the emotional circuit malleable.

As well-being is mainly a function of the environment in the neuropsychotherapeutic literature (Grawe, 2007; Rossouw, 2014), a generic interview topic could be formulated in terms of past episodes and the impact thereof (which could be either negative or positive) on the functioning of participants. Sharing and reflecting on these experiences will already depersonalise the episode, prevent rumination (overactivation of the DMN and $\mathrm{SN}$ ) and thereby enhance the involvement and the development of the EN in the present moment if facilitated with care.

Reframing will set the scene for appreciating the functional role of negative reactions to the outside world as responses that are instrumental to survival. The activation of negative emotions should thus unfold within a safe, supportive environment, where control is still experienced and basic human needs, such as the need for control and orientation, attachment, pleasure maximisation or pain avoidance and self-esteem needs, are met (Grawe, 2007; Rossouw, 2014). The strengths that assisted the AI participants in overcoming past challenges could be identified, or images of a preferred future could be developed, even at this stage. These processes might mirror an approach that is used in the application of neuroscientific principles in narrative therapy (Zimmerman \& Beaudoin, 2015) or cognitive reappraisal (Wang, Chen, \& Han, 2017): this will allow for a vacillation between the activation of those systems that integrate the different systems needed to facilitate change.

Following on from the above, a reframed topic choice can serve as the focus for the discovery phase with strengthbased questions formulated in terms of well-being constructs in positive psychology, for example, resilience, self-efficacy, happiness and gratitude. Care should nonetheless be taken not to view the process as linear. Provision should be made for dealing with any negative emotions which surface during the process. 'The ebb and flow of emotion over the course of therapy reflects the underlying neural rhythms of growth and change' (Cozolino, 2017, p. 48). 
Furthermore, the dream phase of the AI approach, as discussed, will most probably influence the development of the DMN, enhance the connections between the different networks and serve to reinforce learning. However, opportunities for working with feelings could play a more prominent role during the AI process, especially during the dream phase. Identifying, naming and sharing positive and negative feelings that are activated in the body, similar to the practice of focused attention in mindfulness training (Alberts \& Hülsheger, 2015), will not only assist in developing a more effective SN in differentiating what belongs to the self and what belongs to the environment, but also help to integrate the different systems and hence improve well-being (Arden, 2019; Cozolino, 2017).

Additionally, to enhance the integration of the SN and the connection between a healthy SN and EN, introducing 'drench' as a phase of inaction before the design phase, as proposed by Sankarasubramanyan and Wasundhara (2019), is strongly recommended. This state of meditative inaction will allow for the new image to be embodied, and for change to emerge. This could positively influence the quality of the actions of the design and destiny phases.

Setting goals for developing well-being after 'drenching' would probably play an important role in the integration of the different networks. Individualised goals could be formulated in line with the constructs covered during the interviews as these would most probably have been embodied at this stage. The importance of goal setting for life satisfaction, self-esteem and dealing with anxiety has already been established in research on subjective well-being (Diener \& Suh, 1999).

About the destiny phase, it is recommended that the facilitator purposefully includes an opportunity for participants to reflect on the possible external realities that might impact on their well-being. As a form of anticipatory learning (Grieten et al., 2017, p. 104), it can assist in priming the brain for possible future challenges that might be experienced post-intervention. In this sense, it could provide stability through time in the DMN, and hence, assist with building resilience proactively, allowing the EN to deal with those challenges more conductively. The process can be facilitated by using negative images of expected challenges while planning how to deal with those challenges. Visualising negative scenarios, as well as actions to mitigate such challenges, help build neural pathways that could assist individuals with retaining control when affronting the challenges presented by the real world (Rossouw \& Rossouw, 2017).

Lastly, with the operating context in constant flux, stories that are durable with multilayered social contexts are needed to increase the flexible zone between rigidity and the experience of chaos (Arden, 2019). Repetition of the AI process is thus needed to strengthen resilience and for AI to become a living philosophy for well-being.

\section{Practical or managerial implications}

Using AI effectively to enhance well-being will depend on the current state of integration between the different brain systems, and hence the state of participants' well-being at that moment in time. Practising AI as originally conceptualised with its focus on the positive only will most probably enhance the well-being of participants who do not experience stress, by developing their well-being proactively, and building resilience through positive experiences. When using the AI process where participants already experience stress or are traumatised, the intervention needs to be adapted by first appreciating the survival function of the brain and then oscillating between positive and negative experiences, within a safe environment.

\section{Limitations and recommendations}

The academic literature on AI at times differs with the way AI interventions are practised, making it difficult to account for both. Furthermore, neuropsychotherapy is constantly adapting to new findings in the neuroscientific research, influencing the reliability of the method theory. As this study points to a refinement of $\mathrm{AI}$ as intervention per se, it is recommended that empirical studies be conducted on facilitating the refined method and determine the impact thereof, especially during current stressful times.

\section{Conclusion}

To conclude, the author sought to provide an answer to questions around the evaluation and refinement of $\mathrm{AI}$ as a domain theory, for improving well-being in organisations, using neuropsychotherpy as a method theory. Considering the analysis, it is hypothesised that neuropsychotherpy offers a novice contribution to the evaluation and refinement of $\mathrm{AI}$ as an intervention to facilitate well-being in the workplace. Regarding the relevancy of AI, the answer might align with the more recent developments in $\mathrm{AI}$ and the advent of the second wave of positive psychology, and its deviation from a sole focus on positive emotions, traits and institutions (Wong, 2015).

Appreciative inquiry in its more traditional form can thus be used constructively to manage employee well-being but will probably be less effective in changing hard-wired neural circuits for the better. To sustain the well-being of employees, change, repetition and practice are needed. The more recent developments in AI allow us to conclude that, through AI, we are not co-constructing new realities of well-being; we are co-constructing each other to 'becoming' more healthy human beings.

\section{Acknowledgements Competing interests}

The author declares that no competing interest exist. 


\section{Author's contributions}

I declare that I am the sole author of this research article.

\section{Funding information}

This research received no specific grant from any funding agency in the public, commercial, or not-for-profit sectors.

\section{Ethical consideration}

This article followed all ethical standards for carrying out research.

\section{Data availability statement}

The author confirms that the data supporting the findings of this study are available within the article.

\section{Disclaimer}

The views and opinions expressed in this article are those of the author and do not necessarily reflect the official policy or position of any affiliated agency of the author.

\section{References}

Alberini, C.M. (Ed.). (2013). Memory reconsolidation. San Diego, CA: Academic Press.

Alberts, H.J.E.M., \& Hülsheger, U.R. (2015). Applying mindfulness in the context of work: Mindfulness interventions. In J. Reb \& W.B. Atkins (Eds.), Mindfulness in organizations: Foundations, research, applications (pp. 100-132). Cambridge: Cambridge University Press.

Arden, J.B. (2019). Mind-brain-gene: Toward psychotherapy integration. New York, NY: Norton.

Barge, J.K., \& Oliver, C. (2003). Working with appreciation in managerial practice Academy of Management Review, 28, 124-142. https://doi.org/10.5465/ amr.2003.8925244

Barrett, F.T., \& Fry, R.E. (2005). Appreciative inquiry: A positive approach to building cooperative capacity. Chagrin Falls, $\mathrm{OH}$ : Taos.

Biron, C., Karanika-Murray, M., \& Cooper, C.L. (2012). Organizational interventions for stress and well-being: Addressing process and context. London: Routledge.

Buckner, R.L., Andrews-Hanna, J.R., \& Schacter, D.L. (2008). The brain's default mode network: Anatomy, function, and relevance to disease. The New York Academy of Science, 1124(1), 1-38. https://doi.org/10.1196/annals.1440.011

Buckner, R.L., \& Carroll, D.C. (2006). Self-projection and the brain. Trends in Cognitive Sciences, 11(2), 49-57. https://doi.org/10.1016/j.tics.2006.11.004.

Bushe, G.R. (1998). Appreciative inquiry with teams. Organization Development Journal, 16(3), 41-50.

Bushe, G.R. (2001). Five theories of change embedded in appreciative inquiry, in D. Cooperrider, P. Sorenson, D. Whitney, \& T., Yeager (Eds.). Appreciative inquiry: An emerging direction for organization development (pp.117-127). Champaign, IL: Stipes.

Bushe, G.R., \& Kassam, A. (2005). When is appreciative inquiry transformational? A meta-case analysis. Journal of Applied Behavioral Science, 41(2), 161-181.

Bushe, G.R. (2011). Appreciative inquiry: Theory and critique. In D. Boje, B. Burnes, \& J. Hassard (Eds.), The Routledge companion to organizational change (pp. 87-103). Oxford, UK: Routledge.

Chaplin, S. (2006). The placebo response: An important part of treatment. Prescriber, 17(5), 16-22. https://doi.org/10.1002/psb.344

Charag, A.H., \& Fazili, A. (2017). Defining appreciative inquiry: A review of research. Journal of Management Research, 5(1), 1-9.

Cooperrider, D.L., \& Whitney, D. (2005). Appreciative inquiry: A positive revolution in change. San Francisco, CA: Barrett-Koehler.

Cozolino, L. (2017). The neuroscience of psychotherapy: Healing the social brain New York, NY: Norton.

Cozolino, L., \& Sprokay, S. (2006). Neuroscience and adult learning. New Directions for Adult and Continuing Education, 2006(110), 11-19. https://doi.org/10.1002/ ace. 214

Dahlitz, M.J. (2015). Neuropsychotherapy: Defining the emerging paradigm of neurobiologically informed psychotherapy. International Journal of Neuropsychotherapy, 3(1), 47-69. https://doi.org/10.12744/ijnpt.2015.0047-0069
Dahlitz, M.J., \& Rossouw, P.J. (2014). The consistency-theoretical model of mental functioning: Towards a refined perspective. In P.J. Rossouw (Ed.), Neuropsychotherapy: Theoretical underpinnings and clinical applications (peuropsychotherapy: Theoretical

Damasio, A., \& Carvalho, G.B. (2013). The nature of feelings: Evolutionary and neurobiological origins. Nature Reviews Neuroscience, 14(2), 143-152. https:// doi.org/10.1038/nrn3403

Diener, E., \& Suh, E.M., Lucas, R.E., Smith, H.L. (1999). Subjective well-being: The three decades of progress. Psychologial Bulletin, 125(2), 267-302. https://doi. org/10.1037/0033-2909.125.2.276

Ecker, B., Ticic, R., \& Hulley, L. (2012). Unlocking the emotional brain: Eliminating symptoms at their roots, using memory reconsolidation. New York, NY: Routledge.

Ecker, E. (2018). Clinical translation of memory reconsolidation research: Therapeutic methodology for transformational change by erasing implicit emotional learnings driving symptom production. International Journal of Neuropsychotherapy, 6(1), 1-92. https://doi.org/10.12744/ijnpt.2018.0001-0092

Fredrickson, B.L. (2002). Positive emotions. In C.R. Snyder \& S.J. Lopez (Eds.) Handbook of positive psychology (pp. 3-9). New York, NY: Oxford University Press. Fredrickson, B.L. (2009). Positivity. New York, NY: Crown.

Gergen, K.J. (1991). The saturated self. New York, NY: Basic Books.

Gergen, M., \& Gergen, K.J. (Eds.). (2003). Social construction: A reader. London, UK: Sage.

Grawe, K. (2007). Neuropsychotherapy: How the neurosciences inform effective psychotherapy. New York, NY: Psychology Press.

Grieten, S., Lambrechts, F., Bouwen, H., Huybrecchts, J., Fry, R., \& Cooperrider, D. (2018). Inquiring into appreciative inquiry: A conversation with David Cooperrider and Ronald Fry. Journal of Management Inquiry, 27(1), 101-114. https://doi. org/10.1177/1056492616688087

Habermacher, A., Ghadiri, A., \& Peters, T. (2014). The case for basic human needs in coaching: A neuroscientific perspective - The SCOAP Coach Theory. The Coaching Psychologist, 10(1), 1748-1104.

Head, T.C. (2005). A contingency approach to appreciative inquiry: A first small step. In D.L. Cooperrider, P. Sorrenson, D. Witney, \& T. Yeager (Eds.), Appreciative inquiry: Foundations in positive organization development (pp. 401-414). Champaign, IL: Stipes.

Hebb, D.O. (1949). Organization of behavior. New York, NY: Wiley.

Henson, C., \& Rossouw, P. (2013). Brain-wise leadership: Practical neuroscience to survive and thrive at work. Sydney: Learning Quest.

Hirschheim, R. (2008). Some guidelines for the critical reviewing of conceptual papers Journal of the Association for Information Systems, 9(8), 433-441. https://doi. org/10.17705/1jais.00167

Hoskin, D.M., \& McNamee, S. (2006). Making your way. In D.M. Hoskin, \& S. McNamee (Eds.), The social construction of organization (pp. 23-31). Copenhagen: Liber \& Copenhagen Business School Press.

Jaakkola, E. (2020). Designing conceptual articles: Four approaches. AMS Review 10 18-26. https://doi.org/10.1007/s13162-020-00161-0

Kandel, E. (1998). A new intellectual framework for psychiatry. American Jurnal of Psychiatry, 155(4), 457-469. https://doi.org/10.1176/ajp.155.4.457

Lanius, R.A., Frewen, P.A., Tursich, M., Jetly, R., \& McKinnon, M.C. (2015). Restoring large-scale brain networks in PTSD and related disorders: A proposal for large-scale brain networks in PTSD and related disorders: A proposal for neuroscientifically-informed treatment interventions. European Journ
Psychotraumatology, 6, 27313. https://doi.org/10.3402/ejpt.v6.27313

LeDoux, J.E., \& Damasio, A.R. (2013). Emotions and feelings. In E.R. Kandel, J.H. Schwartz, T.M., Jessel, S.A. Siegelbaum, \& A.J. Hudspeth. (Eds.), Principles of neural science (5th edn., pp. 1079-1094). New York, NY: McGraw-Hill.

Levin, P.A. (2008). Healing trauma: A pioneering program for restoring the wisdom of your body. Boulder, CO: Sounds True inc.

Lewis, S. (2014). Creating healthy workplaces. In C. Biron, R.J. Burke, \& C.L. Cooper (Eds.), Creating healthy workplaces: Stress reduction, improved well-being, and organizational effectiveness (pp. 223-235). London: Routledge.

Lewis, S. (2016). Positive psychology and change: How leadership, collaboration and appreciative inquiry create transformational results. New York, NY: John Wiley \& Sons.

Lewis, S., Passmore, J., \& Cantore, S. (2011). Appreciative Inquiry for change management: Using Al to facilitate organizational development. London: Kogan Page.

Lukka, K., \& Vinnari, E. (2014). Domain theory and method theory in management accounting research. Accounting, Auditing \& Accountability Journal, 27(8), 1308-1338. https://doi.org/10.1108/AAAJ-03-2013-1265

MacInnis, D.J. (2011). A framework for conceptual contributions inmarketing. Journal of Marketing, 75(4), 136-154. https://doi.org/10.1509/jmkg.75.4.136

Menon, V., \& Uddin, L.Q. (2010). Saliency, switching, attention and control: A network model of insula function. Brain Structure and Function, 214(5/6), 655-667. https://doi.org/10.1007/s00429-010-0262-0

Moore, S.M., \& Charvat, J. (2007). Promoting health behavior change using appreciative inquiry: Moving from deficit models to affirmation models of care. Family \& Community Health, 30(Supplement 1), s64-s74. https://doi. org/10.1097/00003727-200701001-00009

Nel, K.A., \& Govender, S. (2019). Interventions for shame and guilt experienced by battered women. In C-H. Mayer \& E. Vanderheiden (Eds.), The bright side of shame (pp. 167-183). Cham: Springer.

Nielsen, K., Taris, T.W., \& Cox, T. (2010). Organizational interventions: Issues and challenges. Work \& Stress, 24(3), 219-233. https://doi.org/10.1080/02678373.20 10.519176 
Oliver, C. (2005). Reflexive inquiry: A framework for consultancy practice. London: Karnac.

Orem, S., Binkert, J., \& Clancy, A.L. (2007). Appreciative coaching: A positive process for change. San Francisco, CA: Jossey Bass.

Pillay, S.S. (2011). Your brain and business: The neuroscience of great leaders. New York, NY: W.W. Norton.

Reed, J. (2007). Appreciative inquiry: Research for change. Thousand Oaks, CA: Sage.

Ross, D.A., Arbuckle, M.R., Travis, M.J., Dwyer, J.B., Van Schalkwyk, G.I., \& Ressler K.J. (2017). An integrated neuroscience perspective on formulation and treatment planning for posttraumatic stress disorder: An educational review. AMA Psychiatry, 74(4), 407-415. https://doi.org/10.1001/jamapsychiatry. 2016.3325

Rossi, E.L. (1993). The psychology of mind-body healing. New York, NY: Norton.

Rossouw, J.G., \& Rossouw, P.J. (2017). Executive resilience: Neuroscience for the business of disruption. Sydney: RForce.

Rossouw, P.J. (Ed.). (2014). Neuropsychotherapy: Theoretical underpinnings and clinical applications. Brisbane: Mediros.

Sankarasubramayan, R., \& Wasundhara, J. (2019). Drench - Living the dream before action: A crucial stage in the practice of appreciative inquiry. Organization Development Review, 51(3), 50-56.

Seligman, M.E.P. (2002). Positive psychology, positive prevention, and positive therapy. In C.R. Snyder \& S.J. Lopez (Eds.), Handbook of positive psychology (pp. 3-9). New York, NY: Oxford University Press.

Seligman, M.E.P., \& Csikszentmihalyi, M. (2014). Flow and the foundations of positive psychology. In M.E.P. Seligman \& M. Csikszentmihalyi (Eds.), Positive psychology: An introduction (pp. 279-298). Dordrecht: Springer.
Siegel, D.J. (2012). The developing mind: How relationships and the brain interact to shape who we are (2nd edn.). New York, NY: Guilford Press.

Stratton-Berkessel, R. (2010). Appreciative inquiry for collaborative solutions. San Francisco, CA: Wiley.

Trajkovski, S., Schmied, V., Vickers, M., \& Jackson, D. (2013). Implementing the 4-D cycle of appreciative inquiry in health care: A methodological review. Journal of Advanced Nursing, 69(6), 1224-1234. https://doi.org/10.1111/jan.12086

Wang, Y.M., Chen, J., \& Han, B.Y. (2017). The effects of cognitive reappraisal and expressive suppression on memory of emotional pictures. Frontiers in Psychology, 8, 1921. https://doi.org/10.3389/fpsyg.2017.01921

Watkins, J.M., Mohr, B., \& Kelly, R. (2011). Appreciative inquiry: Change at the speed of imagination (2nd edn.). San Francisco, CA: Wiley and Sons.

Whitney, D., \& Fredrickson, B.L. (2015). Appreciative inquiry meets positive psychology. International Journal of Appreciative Inquiry, 17(3), 18-26. https:// doi.org/10.12781/978-1-907549-24-3

Wilkinson, M. (2017). A whole-person approach to dynamic psychotherapy. In M. Solomon \& D.J. Siegel (Eds.), How people change: Relationships and neuroplasticity in psychotherapy (pp. 73-96). New York, NY: Norton.

Williams, R. (2014). Are we hardwired to be positive or negative? On the capacity to emphasize the negative rather than the positive. Retrieved from https://www. psychologytoday.com/blog/wired-success/201406/are-wehardwired-bepositive-or-negative

Wong, P.T.P. (2015). What is second wave positive psychology and why is it necessary? Retrieved from http://www.drpaulwong.com/what-is-second-wave-positivepsychology-and-why-is-it-necessary/

Zimmerman, J., \& Beaudoin, M. (2015). Neurobiology for your narrative: How brain science influences narrative work. Journal of Systemic Therapies, 34(2), 59-74. https://doi.org/10.1521/jsyt.2015.34.2.59 